\title{
PERIÓDICOS CIENTÍFICOS NA ÁREA DE HISTÓRIA: publicação de autores brasileiros e títulos Qualis A1
}

\author{
SCIENTIFIC JOURNALS IN HISTORY: \\ brazilian author's publication and titles Qualis A1
}

\author{
Rosangela Schwarz Rodrigues ${ }^{1}$ \\ Augiza Karla Boso Anselmo² \\ Dirnele Carneiro Garcez ${ }^{3}$ \\ Laura Lavínia Sabino dos Santos ${ }^{4}$
}

\begin{abstract}
RESUMO
A publicação de artigos científicos é essencial para a comunicação da ciência em todas as áreas do conhecimento. Este artigo estuda os periódicos da área de História classificados como Qualis A1 no período 2013-2016 e os títulos indexados na Web of Science - WoS nos quais autores brasileiros publicaram no mesmo período. 0 objetivo geral é analisar os títulos Qualis A1 e o comportamento de publicação em periódicos qualificados dos autores brasileiros. Os objetivos específicos são: a) descrever as características editoriais dos periódicos de estrato A1 na área de História do Qualis; b) apontar o tipo de acesso dos periódicos de estrato A1 na área de História do Qualis; c) examinar os títulos de periódicos com maior número de artigos com pelo menos um autor brasileiro indexados na Web of Science (WoS). A metodologia é pesquisa exploratória, documental e descritiva. Consultou-se o site do Qualis 2013-2016 e foi realizada busca na Web of Science com a estratégia (CU=Brasil or Brazil) AND (SU=History). Conclui que na área de História a maioria dos 52 títulos registrados como Qualis A1 são brasileiros (35\%), e editados por universidades (23\%), seguido dos títulos ingleses com $29 \%$ editados na maioria por empresas comerciais (19\%). 0 tipo de acesso da maioria dos títulos é aberto sem cobrança de taxas aos autores, modelo dominante no Brasil, os títulos ingleses e norte-americanos são editados por empresas comerciais e a maioria é de subscrição com opção de acesso aberto com taxas, a opção mais comum nesses países em todas as áreas do conhecimento. A presença de grande número de títulos brasileiros classificados como A1 é especificidade da área de História e outras áreas das Ciências Humanas. De um total de 1586 artigos publicados com pelo menos um autor doutor com vínculo institucional brasileiro em títulos indexados na WoS no período 2013 a 2016 foi identificada significativa concentração em periódicos brasileiros (78\%), seguida de títulos ingleses (3\%) e espanhóis (3\%). Os trabalhos estão distribuídos em 144 periódicos de 87 editoras, sendo que a maioria das editoras brasileiras tem apenas um título e muitos artigos e as editoras comerciais vários títulos com poucos artigos cada.
\end{abstract}

Palavras-chave: Comunicação Científica. Periódicos científicos. Qualis História.

\section{ABSTRACT}

The publication of scientific articles is essential for the communication of science in all areas of knowledge. This article studies the periodicals of History classified as Qualis A1 in the period 2013-2016 and the indexed titles in Web of Science - WoS in which Brazilian authors published in the same period. The general objective is to analyze Qualis A1 titles and the behavior of publication in qualified journals of the Brazilian authors. The specific objectives are: a) to describe the editorial characteristics of A1 stratum periodicals in the History of Qualis area; b) to indicate the type of access of the stratum A1 periodicals in the History area of Qualis; c) examine the titles of journals with the highest number of articles with at least one Brazilian author indexed in the Web of Science (WoS). The methodology is exploratory, documentary and descriptive research. The Qualis 2013-2016 website was consulted and Web of Science was searched using the strategy (CU = Brazil or Brazil) AND (SU = History). It concludes that in the area of History most of the 52 titles registered as Qualis A1 are Brazilian (35\%) and edited by universities (23\%), followed by English titles with $29 \%$ edited mostly by commercial companies (19\%). The type of access of most titles is open without charge to authors, the dominant model in Brazil, English, and US titles are edited by commercial companies and most are subscription with the option of open access with rates, the option more common in these countries in all areas of knowledge. The presence of a large number of Brazilian titles classified as A1 is characteristic of the area of History and other areas of Human Sciences. From a total of 1586 articles published with at least one author with Brazilian institutional bond in indexed titles in the WoS in the period from 2013 to 2016 was identified a significant concentration in Brazilian periodicals $(78 \%)$, followed by English titles (3\%) and Spanish ( 3\%). The works are distributed in 144 periodicals of 87 publishers, the majority of the Brazilian publishers has only one title and many articles and the commercial publishers several titles with few articles each.

Keywords: Scientif communication. Scholarly Journals. Qualis. History.

Artigo recebido em 16/01/2019 e aceito para publicação em 28/07/2019.

1 Professora do Programa de Pós-Graduação em Ciência da Informação da Universidade Federal de Santa Catarina, Brasil. Bolsista de Produtividade CNPq. E-mail: rosangela.rodrigues@ufsc.br.

2 Doutoranda no Programa de Pós-graduação em Ciência da Informaç̧ão da Universidade Federal de Santa Catarina, Brasil. Bibliotecária do Instituto Federal de Santa Catarina, Brasil. E-mail: augiza.ifsc@gmail.com.

3 Mestranda no Programa de Pós-Graduação em Ciência da Informação da Universidade Federal de Santa Catarina, Brasil. Bolsista CAPES código 001. E-mail: dirnele.garcez@yahoo.com.br.

4 Bolsista de Iniciação Científica no Bacharelado em Biblioteconomia da Universidade Federal de Santa Catarina, Brasil. E-mail: laura.lavinia-@ hotmail.com. 


\section{INTRODUÇÃO}

A publicação dos resultados da pesquisa em um periódico científico é a principal forma aceita pela academia para registrar a originalidade da investigação e validar os resultados, considerados bons o suficiente para ultrapassar o ceticismo da comunidade científica. (ZIMAN, 1979). Além de ser um canal de comunicação científica, o periódico tornou-se uma instituição social representativa de uma área e os autores que publicam nesses periódicos obtém prestígio, reputação e reconhecimento de seus pares. (MERTON, 2013; LÓPEZ-COZAR, 2017).

López-Cozar (2017) destaca que o periódico se tornou o modo preferido dos cientistas para dar conhecimento dos resultados de suas pesquisas, e assumiu o papel de registro e arquivo público da ciência. 0 periódico é um instrumento-chave na organização, estruturação e institucionalização social de todas as áreas do conhecimento, pois estas publicações são um elemento constituinte da produção e reprodução do conhecimento científico. Os pesquisadores precisam de acesso permanente às pesquisas publicadas anteriormente, pois consultar os artigos científicos permite que cientistas não dupliquem pesquisas ou usem metodologias inapropriadas, o que poderia comprometer a sua própria realização da pesquisa (ABADAL, 2012).

0 reconhecimento do trabalho é materializado essencialmente pelas citações que 0 artigo recebe de outros pesquisadores da comunidade. Isso fundamenta a preferência dos pesquisadores por periódicos de prestígio, cuja visibilidade é maior do que nas publicações menos conceituadas e menos lidas. Isso ocasiona a concentração de artigos em poucos periódicos, que ficam com um poder de seleção maior e publicam as pesquisas de seu interesse. Dessa forma, se tornam mais visíveis e atraem mais submissões, criando, assim, um ciclo virtuoso (MEADOWS, 1998; GUÉDON, 2001).

A comunicação científica é um componente essencial para os avanços da ciência. E por mais importante que seja uma pesquisa, ela não trará contribuições para o progresso da ciência até que seja divulgada, discutida e aceita pela comunidade da área. 0 éthos da ciência é um complexo de valores e normas que se supõem necessários para o cientista moderno. Essas normas "são legitimadas em termos de valores institucionais", independentemente das condições geográficas e políticas das instituições dos cientistas (MERTON, 2013, p. 183).

Cintra; Furnival e Milanez (2017, p. 206) indicam que "devido a sua dependência em relação à herança intelectual, todos os resultados científicos gerados devem ser comuns à sociedade". As 
comunidades científicas possuem características específicas para descrever seus objetos de pesquisa e padrões de comunicação que permitem que os resultados de diferentes estudos sejam comparados e coordenados (WHITLEY, 1984). Ao mesmo tempo que cada área elabora diálogos dentro de uma mesma linguagem, todas as áreas usam os periódicos científicos como suporte para se comunicar, em consórcio com livros e eventos científicos em diversas proporções . (MUGNAINI; POBLACIÓN, 2010).

A partir da Segunda Guerra Mundial, o artigo científico vira uma "commodity" de prestígio entre os cientistas, e os periódicos passam a ter maior importância, pois as editoras comerciais viram um nicho mercadológico promissor. Os periódicos foram colocados em um campo privado que tem como interesse e principal foco o lucro financeiro. (GUÉDON, 2001). Grandes grupos editoriais como Elsevier, Springer e Wiley comandam o mercado da comunicação científica internacional, onde são cobrados milhões de dólares em assinaturas. Artigos de livre acesso também podem ser incluídos em títulos de subscrição desde que 0 autor pague uma taxa chamada Article Processing Charges (APCs) (LARIVIÈRE; HAUSTEN; MONGEON, 2015).

No Brasil, o Qualis exerce forte influência sobre o prestígio de um periódico científico, o que interfere na quantidade de submissões e, consequentemente, na qualidade dos artigos publicados. (COSTA; YAMAMOTO, 2008; LEITE; CODATO, 2013). O Qualis é utilizado pela Coordenação de Aperfeiçoamento de Pessoal de Nível Superior - CAPES para "estratificação da qualidade da produção intelectual dos programas de pós-graduação". 0 Qualis foi gerado para responder às necessidades do sistema de avaliação em classificar os títulos dos periódicos onde os autores publicam. Partindo da análise da classificação dos periódicos científicos, o Qualis atribui graus de qualidade aos artigos com base no periódico onde foi publicado, e não na qualidade do artigo em si. (MINISTÉRIO..., 2017).

Os objetivos do Qualis são "[...] contribuir decisivamente para a avaliação dos programas de pós-graduação e sinalizar aos pesquisadores que procurem se adequar aos perfis dos periódicos mais bem-conceituados, induzindo o foco de pesquisa e veículo de publicação [...]." (LINS; PESSÔA, 2010, p. 21). Dessa forma, o sistema Qualis tem como efeito colateral influenciar o pesquisador na escolha de onde ele deve publicar (ERDMANN et. al., 2009).

Mesmo que a CAPES (MINISTÉRIO..., 2018) oriente que “a função do Qualis é exclusivamente para avaliar a produção científica dos programas de pós-graduação. Qualquer outro uso fora do 
âmbito da avaliação dos programas de pós-graduação não é de responsabilidade da CAPES", é inegável o efeito do estrato Qualis na escolha dos títulos preferenciais de submissão, logo da capacidade de seleção de trabalhos pelos editores e do rigor que pode ser exigido dos artigos que são publicados.

E na produção Intelectual, o MEC (MINISTÉRIO..., 2016b, p. 12, grifo nosso) no item 4.1 informa que o maior peso da avaliação são as "publicações qualificadas do Programa por docente permanente. Considerar a qualificação do programa no tocante à publicação de artigos, capítulos e livros segundo a avaliação dos mesmos pela área". Por isso, os critérios para atribuição de Qualis A1, determinadas pelos representantes das áreas tornam-se essenciais para a avaliação do desempenho da publicação de todos os pesquisadores das áreas e de suas instituições. O MEC (MINISTÉRIO..., 2016a, p. 05, grifo nosso) ressalta que:

A Área de História levará em consideração, de maneira suplementar, os indicadores bibliométricos JCR, SJR e, especialmente, os índices H fornecidos pelo Google Scholar (haja vista sua universalidade), sobretudo para a inserção dos periódicos nos estratos mais elevados (A1, A2 e B1). Os periódicos mobilizados pela área que integrem bases relevantes, como Web of Science e Scopus, serão candidatos aos estratos mais elevados.

A fórmula da CAPES para distribuição de Qualis de todas as áreas segue os parâmetros de atribuição dos estratos aprovados pelo Conselho Técnico-Científico da Educação Superior, a saber: A1 $<A 2 ; A 1+A 2 \leq 25 \%$ do total de $A 1$ a B5; $A 1+A 2+B 1 \leq 50 \%$ do total de $A 1$ a B5 e B2 + B3 + B4 + B5 $\geq 50 \%$ do total de $A 1$ a B5. Cuja pontuação é a seguinte: $A 1=100 ; A 2=85 ; B 1=70 ; B 2=55 ; B 3=40$; B4 = 25; B5 = 10 (MINISTÉRIO..., 2016a). A limitação na quantidade de títulos A1 e A2 em 25\% do total de títulos onde todos os pesquisadores da área publicaram cria uma relação direta entre a diversidade de títulos onde publicam as áreas e o número possível de títulos em cada estrato.

Publicar um artigo científico em um periódico em destaque da área garante prestígio, visibilidade e reputação para 0 autor e para a instituição ao qual está vinculado, e faz a diferença no número de citações que a pesquisa recebe, na concorrência por uma posição na academia, na obtenção de verbas para futuras pesquisas, na progressão funcional do pesquisador e também para a nota que o programa de pós-graduação ao qual está vinculado recebe da CAPES. Por isso, verificar o Qualis da revista na sua área, antes de submeter o artigo é algo fundamental para os pesquisadores.

Os docentes permanentes na área de História aumentaram em 122\% em um período de dez anos, somando 1.464 professores em 2015. Isso se deve ao fato de que este foi um período de expansão das universidades e da pós-graduação no Brasil, além disso, ampliou o número de 
titulados no mestrado em 123\% (1.058) e no doutorado em 61\% (382) no período de 2005 a 2015 (MINISTÉRIO..., 2016b). Em consequência disso, ampliou-se o número de autores potenciais na área e a quantidade de publicações.

Assim, a questão de pesquisa que se apresenta é qual o cenário da publicação em periódicos da área de História? Para responder à questão de pesquisa, o objetivo geral deste artigo é analisar os títulos Qualis A1, considerados de maior prestígio, e o comportamento de publicação em periódicos qualificados dos autores brasileiros. Tendo como período selecionado o quadriênio 2013 a 2016, os objetivos específicos deste estudo são:

a) Descrever as características editoriais dos periódicos de estrato A1 na área de História do Qualis;

b) Apontar o tipo de acesso dos periódicos de estrato A1 na área de História do Qualis;

c) Examinar os títulos de periódicos com maior número de artigos com pelo menos um autor brasileiro indexados na Web of Science (WoS).

\section{METODOLOGIA}

Esta é uma pesquisa exploratória e descritiva, com coleta de dados, onde não há influências do pesquisador no assunto analisado. (SAMPIERI; COLLADO; LUCI0, 2006; CRESWELL, 2010). Quanto à forma de abordagem do problema, esta pesquisa pode ser caracterizada como sendo de métodos mistos e documentais. Para tanto, esta pesquisa foi dividida em duas etapas, na primeira foram analisados os periódicos da área de história na Plataforma Sucupira com os termos Evento de Classificação: Classificações de periódicos quadriênios 2013 - 2016; classificação A1. Esta busca foi realizada em abril de 2018 e recuperou 52 periódicos, depois do descarte de 27 repetidos. 0 propósito desta lista é identificar os títulos que a área considera de maior prestígio.

Em um segundo momento, foram analisados os artigos publicados, realizou-se a coleta de dados na principal coleção do WoS utilizando a estratégia de busca: (CU=Brasil or Brazil) and SU=(History)); sendo que CU significa país/região e SU é a área do conhecimento. Restringiu-se o resultado pelo tipo de documento utilizando a opção: "article" (artigo), quanto aos idiomas optou-se por: "all languages" (todas as línguas). 0 período estipulado foi 0 mesmo, de 2013 a 2016. Esta busca foi realizada em maio de 2018 e recuperou 1586 artigos válidos. Conforme Figura 01. Aqui o propósito foi identificar em quais títulos indexados na WoS os autores brasileiros publicaram no mesmo período. 
Figura 01: Estratégia de busca utilizada Web of Science

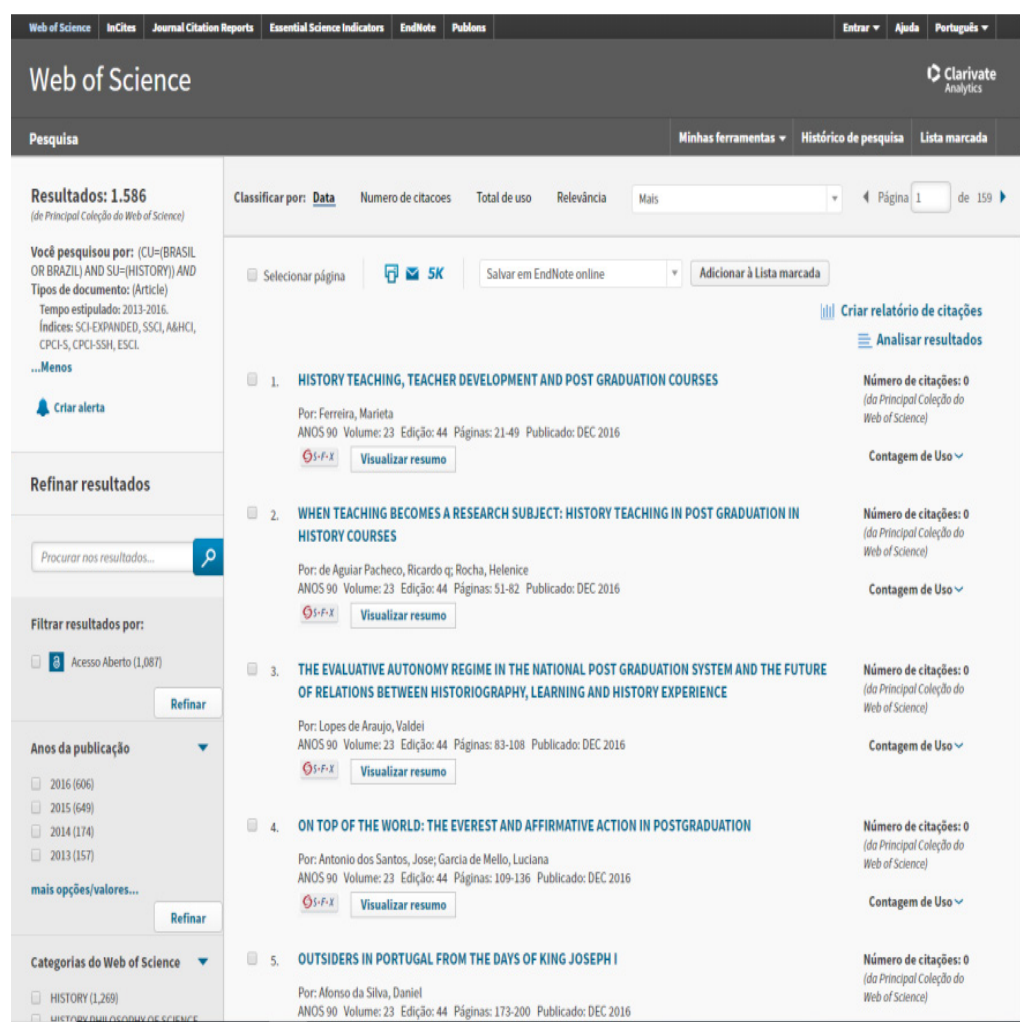

Fonte: Web of Science (23 maio 2018)

A WoS foi escolhida por ser considerada a base onde estão os títulos de maior prestígio de todas as áreas do conhecimento, inclusive a História, assumindo assim que todos os periódicos e artigos atendem critérios internacionalmente aceitos. 0 instrumento de coleta de dados foi uma ficha documental, elaborada no Microsoft Office Excel 2007, e os dados foram processados por meio de estatística descritiva.

\section{RESULTADOS E DISCUSSÃO}

Na primeira parte da análise foi identificado um total de 52 periódicos no estrato A1 na área de História do Qualis, quadriênio 2013 a 2016. 0 país que possui maior número de periódicos indexados é o Brasil, com um total de 18 títulos (34,62\%), seguido do Reino Unido, com 15 títulos (28,85\%), Estados Unidos, com oito títulos (15,38\%), Colômbia, Espanha e Holanda, com dois títulos cada um (3,85\%) e Portugal, Chile, Argentina, Japão e Suíça com um título cada um (1,92\%).

Examinando a Tabela 01, a seguir, percebe-se que as editoras universitárias são as responsáveis pelo maior número de títulos, com 23 (44, 23\%) do total, conforme Rosa et. al. (2013, p. 155), "a 
produção das editoras universitárias está voltada para obras de diversas áreas do conhecimento, oriundas, em sua grande maioria, de pesquisas desenvolvidas nas IES". Os resultados mostram diferença significativa com as pesquisas efetuadas por Coleman (2007) e por McGuigan e Russel (2008) no cenário norte americano que apontam a liderança de artigos publicados em periódicos de editoras comerciais, na maioria das áreas. Majoritariamente, os periódicos Qualis A1 de História, são brasileiros e o acesso aberto com editoras universitárias é predominante no país, confirmando os resultados apontados por Rodrigues e Abadal (2014), Mueller (2010), Mugnaini, Digiampietri e MenaChalco (2014) e Packer (2014). Em seguida, os títulos de editoras comerciais, com 18 (34,62\%), as Associações, com oito (15,38\%), os institutos de pesquisa, com dois $(3,85 \%)$ e um classificado em outros por ser considerado um conjunto de instituições responsáveis pela editoria de editoras pra um mesmo periódico: Sociedade Brasileira de Teoria e História da Historiografia, Universidade Federal do Estado do Rio de Janeiro e Universidade Federal de Ouro Preto. As informações das Editoras foram coletadas no site das revistas.

As entidades editoriais que abrigam três ou mais periódicos são comerciais e somam 17 títulos ou $32,69 \%$ do total. As demais são universidades, com nove revistas ou $17,32 \%$ do total. As associações têm dois títulos e institutos de pesquisa tem um título.

Tabela 01 - Distribuição dos periódicos Qualis A1 de História, quadriênio 2013 a 2016, por tipo de entidade editorial e país

\begin{tabular}{|c|c|c|c|c|c|c|c|c|c|c|c|c|}
\hline $\begin{array}{l}\text { Entidade } \\
\text { Editorial }\end{array}$ & Uni & sidades & & $\begin{array}{l}\text { oras } \\
\text { rciais }\end{array}$ & Ass & ações & & $\begin{array}{l}\text { os de } \\
\text { lisa }\end{array}$ & & tros & & otal \\
\hline País & $\mathbf{N}$ & $\%$ & $\mathbf{N}$ & $\%$ & $\mathrm{n}$ & $\%$ & $\mathrm{n}$ & $\%$ & $\mathbf{N}$ & $\%$ & $\mathbf{N}$ & $\%$ \\
\hline Brasil & 12 & 23,08 & 0 & 0,00 & 4 & 7,69 & 1 & 1,92 & 1 & 1,92 & 18 & 34,62 \\
\hline $\begin{array}{l}\text { Estados } \\
\text { Unidos }\end{array}$ & 3 & 5,77 & 3 & 5,77 & 2 & 3,85 & 0 & 0,00 & 0 & 0,00 & 8 & 15,38 \\
\hline $\begin{array}{l}\text { Reino } \\
\text { Unido }\end{array}$ & 3 & 5,77 & 10 & 19,23 & 2 & 3,85 & 0 & 0,00 & 0 & 0,00 & 15 & 28,85 \\
\hline Colômbia & 2 & 3,85 & 0 & 0,00 & 0 & 0,00 & 0 & 0,00 & 0 & 0,00 & 2 & 3,85 \\
\hline Portugal & 1 & 1,92 & 0 & 0,00 & 0 & 0,00 & 0 & 0,00 & 0 & 0,00 & 1 & 1,92 \\
\hline Chile & 1 & 1,92 & 0 & 0,00 & 0 & 0,00 & 0 & 0,00 & 0 & 0,00 & 1 & 1,92 \\
\hline Argentina & 1 & 1,92 & 0 & 0,00 & 0 & 0,00 & 0 & 0,00 & 0 & 0,00 & 1 & 1,92 \\
\hline Japão & 0 & 0,00 & 1 & 1,92 & 0 & 0,00 & 0 & 0,00 & 0 & 0,00 & 1 & 1,92 \\
\hline Espanha & 0 & 0,00 & 1 & 1,92 & 0 & 0,00 & 1 & 1,92 & 0 & 0,00 & 2 & 3,85 \\
\hline Holanda & 0 & 0,00 & 2 & 3,85 & 0 & 0,00 & 0 & 0,00 & 0 & 0,00 & 2 & 3,85 \\
\hline Suíça & 0 & 0,00 & 1 & 1,92 & 0 & 0,00 & 0 & 0,00 & 0 & 0,00 & 1 & 1,92 \\
\hline $\begin{array}{c}\text { Total de } \\
\text { periódicos }\end{array}$ & 23 & 44,23 & 18 & 34,62 & 8 & 15,38 & 2 & 3,85 & 1 & 1,92 & 52 & 100,00 \\
\hline
\end{tabular}

Fonte: Dados da pesquisa (2018). 
A identificação dos periódicos por país mostrou títulos provenientes da América do Norte (Estados Unidos), América do Sul (Brasil, Chile, Colômbia e Argentina), Ásia (Japão) e Europa (Espanha, Portugal, Holanda, Reino Unido e Suíça). A predominância do Reuni Unido, com 15 títulos, e da América do Norte, com oito títulos, na publicação de artigos científicos é fato corrente na ciência (UNESCO, 2015).

A área de História no Brasil ultrapassa as barreiras de publicação enfrentadas pelas regiões periféricas, América Latina, África, Ásia e Europa oriental, identificadas por Mueller e Oliveira (2003, p. 59) abordadas no modelo centro-periferia de Shils (1992) que indica a sociedade como guardiã de um centro, de valores e crenças, que afetam, de várias formas, a vida da população de periferias. Na área de História os periódicos da América Latina estão em posição equivalente à dos países ditos centrais no estrato Qualis A1. Conforme os autores "as ligações entre centro e periferia configuram uma rede de comunicações e influência, onde o poder é distribuído de maneira desigual e onde a disputa pela hegemonia sempre existe" (MUELLER; OLIVEIRA, 2003, p. 60).

0 estudo realizado por Minniti, Santoro e Belli (2018) focando a análise das publicações da América Latina e Caribe de acesso aberto indexados na WoS vai ao encontro dos dados dessa pesquisa, registrando o Brasil como o país mais produtivo, em números absolutos, com $69,70 \%$ do total dos documentos, seguido pelo México com 10,23\%, Argentina, 6,84\%, Colômbia, 6,05\% e Chile com 5,12\% da amostra da WoS (MINNITI; SANTORO; BELLI, 2018, p. 1919 e 1920).

Mueller (2010) investigou a relação entre as áreas de conhecimento, financiamento e editoras das revistas brasileiras integrantes da base Scielo em 2008 e identificou 193 periódicos; destes, 47\% são publicados por associações científicas e 35\% por universidades. Na área de História Qualis A1 no Brasil predominam os periódicos publicados por universidades, 23,08\%, seguido das associações $7,69 \%$. As pesquisas concordam com o estudo de Rodrigues e Oliveira (2012) que informam que mais de 90\% dos títulos brasileiros são publicados em acesso aberto por universidades e associações.

A Tabela 02, a seguir, mostra a distribuição de periódicos Qualis A1 de História, quadriênio 2013 a 2016, por entidade editorial. A Elsevier é editora que tem maior número de títulos, sete $(13,46 \%)$, enquanto a Sage mantém quatro (7,69\%). A Taylor \& Francis, a Springer e a Cambridge University Press concentram três $(5,77 \%)$ periódicos cada, Universidade Federal do Rio Grande do Sul, a Duke University Press e a Universidade Federal do Rio de Janeiro abrigam dois (3,85\%) periódicos cada da área da História com Qualis A1. Ressalta-se que 26 (50\%) das entidades editoriais possuem somente um periódico. 0 Brasil tem duas editoras universitárias com dois títulos cada. As 
entidades editoriais que abrigam três ou mais periódicos, são comerciais, que somadas representam $17(32,69 \%)$ do total. As demais são universidades, que representam nove títulos ou 17,32\% do total. A dispersão de títulos segue o mesmo padrão em várias áreas do conhecimento, com as editoras comerciais com o maior número de títulos, o que lhes permite ganho em escala e controle sobre o que é publicado.

Tabela 02 - Distribuição do tipo de acesso de periódicos Qualis A1 de História, quadriênio 2013 a 2016, por país

\begin{tabular}{|c|c|c|c|c|c|c|c|c|}
\hline \multirow{2}{*}{$\begin{array}{c}\text { Tipo de Acesso } \\
\text { País }\end{array}$} & \multicolumn{2}{|c|}{$\begin{array}{c}\text { Acesso aberto } \\
\text { sem taxas }\end{array}$} & \multicolumn{2}{|c|}{ Subscrição } & \multicolumn{2}{|c|}{$\begin{array}{l}\text { Subscrição com } \\
\text { opção } \\
\text { taxas de autor }\end{array}$} & \multicolumn{2}{|c|}{ Total } \\
\hline & $\mathbf{N}$ & $\%$ & $\mathrm{n}$ & $\%$ & $\mathbf{N}$ & $\%$ & $\mathbf{n}$ & $\%$ \\
\hline Brasil & 18 & 34,62 & 0 & 0,00 & 0 & 0,00 & 18 & 34,62 \\
\hline Reino Unido & 0 & 0,00 & 2 & 3,85 & 13 & 25,00 & 15 & 28,85 \\
\hline Estados Unidos & 1 & 1,92 & 2 & 3,85 & 5 & 9,62 & 8 & 15,38 \\
\hline Colômbia & 2 & 3,85 & 0 & 0,00 & 0 & 0,00 & 2 & 3,85 \\
\hline Espanha & 1 & 1,92 & 0 & 0,00 & 1 & 1,92 & 2 & 3,85 \\
\hline Holanda & 0 & 0,00 & 0 & 0,00 & 2 & 3,85 & 2 & 3,85 \\
\hline Portugal & 1 & 1,92 & 0 & 0,00 & 0 & 0,00 & 1 & 1,92 \\
\hline Chile & 1 & 1,92 & 0 & 0,00 & 0 & 0,00 & 1 & 1,92 \\
\hline Argentina & 1 & 1,92 & 0 & 0,00 & 0 & 0,00 & 1 & 1,92 \\
\hline Japão & 0 & 0,00 & 0 & 0,00 & 1 & 1,92 & 1 & 1,92 \\
\hline Suíça & 0 & 0,00 & 0 & 0,00 & 1 & 1,92 & 1 & 1,92 \\
\hline Total & 25 & 48,08 & 4 & 7,69 & 23 & 44,23 & 52 & 100,00 \\
\hline
\end{tabular}

Fonte: Dados da pesquisa (2018)

Quanto ao tipo de acesso dos periódicos de estrato A1 na área de História do Qualis, conforme Tabela 02, verificou-se que dos 52 títulos, 25 (48,08\%) são de acesso aberto, todos sem cobrança de taxas para os autores, $23(44,23 \%)$ periódicos com subscrição com opção de taxas de autor e quatro (7,69\%) apenas por subscrição. Nota-se que o Brasil lidera o ranking com 18 (34,62\%) periódicos de acesso aberto, seguido da Colômbia com dois (3,85\%) periódicos de acesso aberto, Estados Unidos, Chile, Argentina, Espanha e Portugal possuem um (1,92\%) periódico sem taxas, cada um; Japão, Holanda, Reino Unido e Suíça não possuem periódicos de acesso aberto estrato A1 na área de História do Qualis.

Packer (2011) evidencia que 0 acesso aberto se baseia no fato da pesquisa receber recursos públicos, na maioria das vezes, e é essencial para os países em desenvolvimento, em função dos altos custos de subscrição que limitam o acesso; segundo Packer (2014, p. 320) muitos dos periódicos 
no Brasil atuam no "fluxo internacional da comunicação científica, com predominância do acesso aberto aos textos completos dos resultados das pesquisas [...]". Packer e Meneghini (2014) apontam que a América Latina lidera, no volume de títulos em acesso aberto, indexados nas bases de dados internacionais Scopus e WoS.

Já o Reino Unido possui 13 (25\%) periódicos com subscrição com opção de taxas de autor e dois $(3,85 \%)$ com subscrição, seguido dos Estados Unidos cinco $(9,62 \%)$ periódicos com subscrição com opção de taxas de autor e dois (3,85\%) com subscrição. Holanda possui dois (3,85\%) periódicos com subscrição com opção de taxas de autor, seguido de Espanha, Japão e Suíça com um (1,92\%) periódico, cada um, com subscrição com opção de taxas de autor.

Collazo-Reyes (2014, p. 204) investigou o crescimento do número de revistas indexadas na América Latina e Caribe (AL\&C) e 0 efeito no impacto de cada país constando que $88,8 \%$ dos artigos em periódicos brasileiros correspondem a publicações de autores brasileiros, em comparação com os países da AL\&C. Embora se publique muito internamente, percebe-se que a WoS tem tido um aumento na abrangência da produção científica brasileira. (LETA, 2012; COLLAZO-REYES, 2014; SILVA, ET. AL, 2018).

Collazo-Reyes (2014, p. 204, tradução nossa) corrobora com essa ideia afirmando que 0 "aumento no número de artigos nas revistas internacionais na WoS também corresponde a um grande aumento da indexação em bases internacionais dos títulos brasileiros".

Quanto à distribuição dos tipos de acesso Qualis A1 de História por entidade editorial, observa-se que a universidade é mais comum entre periódicos de Acesso Aberto, os demais são provenientes de associações e institutos de pesquisa. As editoras comerciais aparecem nos primeiros lugares com periódicos com subscrição com opção de taxas do autor, sendo estas: Elsevier com sete $(13,46 \%)$ periódicos com subscrição com opção de taxas do autor; Sage com quatro $(7,69 \%)$ periódicos com subscrição com opção de taxas do autor; Taylor \& Francis e Springer com três $(5,77 \%$ \%) periódicos com subscrição com opção de taxas do autor, cada uma.

As características editoriais dos títulos $\mathrm{A} 1$ da área de História podem ser descritos como publicados por instituições brasileiras (32\%), sendo a maioria por universidades (23\%). Na sequência vem os títulos do Reino Unido com 28,85\%, publicados por empresas comerciais (19\%). Cabe destacar a baixa presença de títulos americanos (15\%) e pequena participação de oito outros países, todos com menos de $5 \%$ dos títulos listados. 0 tipo acesso dos períodos depende da localização geográfica, todos 
os títulos brasileiros estão em Acesso Aberto sem cobrança de taxas aos autores, o que representa 35\% do total. A totalidade dos títulos do Reino Unido é de subscrição, a maioria com opção de acesso aberto mediante pagamento de taxas, o que corresponde ao movimento global das editoras comerciais. Podese presumir importante percentual de artigos no idioma português e um cenário nacional com títulos brasileiros considerados de qualidade pela comunidade científica. Diferente da área de Agrárias, onde os melhores periódicos brasileiros estão classificados como B1 (OLIVEIRA, RODRIGUES, MATIAS, 2017) e da Ciências Biológicas, onde todos os títulos A1 são estrangeiros. (NEUBERT, RODRIGUES, MULLER, 2017).

Para adensar a discussão sobre a área na segunda parte da análise foram identificados um total de 1586 artigos da área de História com pelo menos um autor brasileiro, publicados em 144 periódicos indexados na WoS, sendo 15 classificados como Qualis A1 na área de História, 07 como A2 e 18 como B1; os demais periódicos obtiveram B2 (16); B3 (09); B4 (04); B5 (02); C (03); 45 periódicos estavam avaliados em áreas diferentes de História e 25 não possuíam registro em nenhuma área do Qualis.

Apesar que Fico, Wasserman e Magalhaes (2018, p. 282,) ressaltarem que:

0 novo processo de avaliação dos periódicos da área de História apresenta uma série de características que convém destacar: no caso da atribuição dos estratos A1, A2 e B1, foi considerada a inserção em bases de dados relevantes, notadamente Web of Science, Scopus e Scielo; a existência de fatores de impacto foi considerada após a análise feita pelos avaliadores. Tais parâmetros foram utilizados para detectar discrepâncias flagrantes.

Observa-se inconsistências na classificação títulos no Qualis, pois apenas 40 do total de 144 periódicos indexados na WoS, estão classificados no estratos mais alto.

A Tabela 03, a seguir, mostra os títulos com maior número de artigos, e seus respectivos Qualis. Nota-se que os três primeiros títulos de periódicos com a maior quantidade de artigos indexados são brasileiros e Qualis A1, sendo que o periódico História, Ciências, Saúde - Manguinhos somou 211 (13,30\%) artigos; seguido de História UNISINOS com 98 (6,18\%) dos artigos e a Revista Brasileira de História com 95 (5,99\%) dos artigos.

Nota-se a significativa concentração de artigos em poucos títulos, os periódicos com mais de 10 artigos cada totalizam 25 (17,36\%) títulos, sendo que a grande maioria, (119 ou 82,34\%) publicaram menos de 10 artigos de autores brasileiros cada entre 2013 e 2016. Observa-se, ainda que o montante de artigos publicados por estes 25 periódicos foi de 1343 (84,68\%) do total. 
Tem-se, do total desses 25 periódicos a seguinte classificação Qualis: A1 seis periódicos, A2 quatro periódicos; B1 três periódicos; B2 cinco periódicos; B3 cinco periódicos; B4 um periódico e um periódico que não identificamos Qualis na área de História, mas está registrado em outras áreas.

Tabela 03 - Títulos de periódicos com maior número de artigos indexados na WoS, quadriênio 2013 a 2016 de autores brasileiros, e seus respectivos Qualis na área de História

\begin{tabular}{|l|c|c|c|}
\hline \multicolumn{1}{|c|}{ Título do Periódico } & \multicolumn{2}{|c|}{ Artigos } & \\
\hline & $\mathrm{n}$ & $\%$ & Qualis \\
\hline História Ciências Saúde-Manguinhos & 211 & 13,30 & $\mathrm{~A} 1$ \\
\hline História Unisinos & 98 & 6,18 & $\mathrm{~A} 1$ \\
\hline Revista Brasileira de História & 95 & 5,99 & $\mathrm{~A} 1$ \\
\hline História e Cultura & 84 & 5,30 & $\mathrm{~B} 3$ \\
\hline $\begin{array}{l}\text { AEDOS - Rev do Corpo Discente do Programa de Pós-Graduação em } \\
\text { História da UFRGS }\end{array}$ & 77 & 4,85 & $\mathrm{~B} 3$ \\
\hline Tempo-Niterói & 70 & 4,41 & $\mathrm{~A} 1$ \\
\hline Antíteses & 66 & 4,16 & $\mathrm{~B} 1$ \\
\hline Tempo e Argumento & 64 & 4,04 & $\mathrm{~A} 2$ \\
\hline História da Historiografia & 51 & 3,22 & $\mathrm{~A} 1$ \\
\hline Patrimônio e Memória & 50 & 3,15 & $\mathrm{~B} 2$ \\
\hline Estudios Historicos & 48 & 3,03 & $\mathrm{~B} 2$ \\
\hline História Histórias & 48 & 3,03 & $\mathrm{~B} 3$ \\
\hline METIS - História e Cultura & 47 & 2,96 & $\mathrm{~B} 2$ \\
\hline Estudos Ibero-Americanos & 45 & 2,84 & $\mathrm{~A} 2$ \\
\hline Cadernos de História & 41 & 2,59 & $\mathrm{~B} 3$ \\
\hline TOPOI - Revista de História & 41 & 2,59 & $\mathrm{~A} 1$ \\
\hline $\begin{array}{l}\text { PASSAGENS-International Review of Political History and Legal } \\
\text { Culture }\end{array}$ & 34 & 2,14 & $\mathrm{~B} 2$ \\
\hline Revista História-Debates e Tendências & 34 & 2,14 & $\mathrm{~B} 2$ \\
\hline CORDIS - Revista Eletrônica de História Social da Cidade & 33 & 2,08 & $\mathrm{~B} 3$ \\
\hline Anos 90 & 28 & 1,77 & $\mathrm{~A} 2$ \\
\hline NAVIGATOR - Subsídios para a História Marítima do Brasil & 24 & 1,51 & $\mathrm{~B} 4$ \\
\hline Science \& Education & 17 & 1,07 & $\mathrm{Nã0}$ \\
\hline Revista Portuguesa de Historia & 11 & 0,69 & $\mathrm{~A} 2$ \\
\hline History of Education \& Childrens Literature & 13 & 0,82 & $\mathrm{~B} 1$ \\
\hline International Journal of The History of Sport & $\mathbf{1 5 8 6}$ & $\mathbf{1 0 0 , 0 0}$ & \\
\hline${ }^{\circ}$ Outros & & \\
\hline & & $\mathrm{B} 1$ \\
\hline
\end{tabular}

Fonte: Dados da Pesquisa (2018)

*Outros: 119 títulos de periódicos com até 10 artigos cada.

Sobre os necessários questionamento às listas do Qualis, Benthiem (2018, p. 12) citam 0 exemplo da revista Acta Histochemica, indexada na WoS: 
[...] especializada na química celular e molecular. Compartilhando com o JAAS uma diversidade institucional altíssima - embora, repito, não-mensurável em termos de programas de pósgraduação -, estando ainda atrelada a bases de indexação internacionais e tendo um fator de impacto elevado (acima de 1.5 para 0 quadriênio avaliado), esta revista editada pela Elsevier recebeu o qualis B3 em História, o menor em comparação às demais áreas do conhecimento.

Nesta pesquisa observaram-se casos parecidos, o periódico História e Cultura (ISSN 22386270), por exemplo, está indexado na WoS e seu Qualis varia entre B1 e B5, dependendo da área, no caso da História possui Qualis B3. Nesse caso cabe questionar se por estar indexado na WoS e 0 documento de área da CAPES informar os critérios para aumento do Qualis, este poderia estar entre os níveis mais altos de classificação no Qualis?.

A primeira etapa da pesquisa recuperou 52 periódicos Qualis A1 da área de História no Sucupira e no segundo momento, identificou 144 periódicos da área de História indexados na Web of Science com pelo menos um autor com declarado com vínculo institucional brasileiro. Dos 52 periódicos recuperados na primeira etapa na lista Qualis A1, 42 estão indexados na WoS, sendo que destes 42 , 15 foram identificados na WoS com os termos de busca utilizados na segunda parte da pesquisa. Os 10 periódicos que não estão na WoS são: Educação e Realidade, Estudos Feministas, Etnográfica, História (São Paulo), Revista Brasileira de Ciências Sociais, Revista Brasileira de Educação, Revista de História, Sociologias, Varia História e Vibrant sendo que todos estão indexados tanto na SCOPUS quanto na SciELO. Se compararmos o número de títulos registrados no Qualis A1 com a quantidade de artigos identificados na busca do WoS temos a seguinte proporção: dos 25 títulos de periódicos que possuem mais de 10 artigos publicados cada somam um total de 1343 artigos indexados. Destes 1343 artigos temos a seguinte classificação Qualis para seus periódicos: A1: 566 (42,14\%) artigos, A2: 148 (11,02\%) artigos; B1: 92 (6,85\%) artigos; B2: 213 (15,86\%) artigos; B3: 283 (21,07\%) artigos; B4: 24 (1,79\%) artigos e obtivemos $17(1,27 \%)$ artigos publicados em periódicos que não possuem Qualis na área de história, mas em outras áreas. Cumpre destacar que a indexação é dinâmica e a lista 2013-2016 foi o retrato de um dado momento, alterações podem ter ocorrido no período.

0 estudo de Fico, Wasserman e Magalhaes (2018) discute os artigos publicados pela área de História, onde consideraram o período da Avaliação Quadrienal 2017 (2013 a 2016) da CAPES e obtiveram o total de 4.779 artigos publicados por 1368 professores permanentes dos programas de pós-graduação brasileiros, sendo que 1714 artigos foram publicados em revistas A1, A2 e B1. 
Esses resultados estão alinhados com os resultados desta pesquisa tendo em vista que os 4 títulos de periódicos com maiores números de artigos indexados na WoS representam 30,77\% das publicações dos artigos da área.

Pode-se verificar na Tabela 04, a seguir, os países dos periódicos que apresentaram maior número de artigos indexados na WoS. A grande maioria dos artigos foi publicada por títulos editados no Brasil com 1241 (78,25\%) artigos, seguido pela Inglaterra com 53 (3,34\%\%) artigos, Espanha com 51 (3,22\%) artigos, Estados Unidos e Uruguai com 48 (3,03\%) artigos cada um, Holanda com 46 $(2,90 \%)$ artigos.

Tabela 04 - Artigos indexados na WoS de 2013 a 2016, classificados por países de origem dos periódicos, quantidade de títulos e editoras

\begin{tabular}{|c|c|c|c|c|c|c|}
\hline País & \multicolumn{2}{|c|}{ Artigos } & \multicolumn{2}{c|}{ Periódicos } & \multicolumn{2}{c|}{ Editoras } \\
\hline & $\mathbf{N}$ & $\mathbf{0}$ & $\mathbf{N}$ & $\mathbf{0}$ & $\mathbf{N}$ & $\%$ \\
\hline Brasil & 1241 & 78,25 & 20 & 13,89 & 17 & 19,54 \\
\hline Inglaterra & 53 & 3,34 & 27 & 18,75 & 9 & 10,34 \\
\hline Espanha & 51 & 3,22 & 20 & 13,89 & 15 & 17,24 \\
\hline EUA & 48 & 3,03 & 27 & 18,75 & 13 & 14,94 \\
\hline Uruguai & 48 & 3,03 & 1 & 0,69 & 1 & 1,15 \\
\hline Holanda & 46 & 2,90 & 12 & 8,33 & 1 & 1,15 \\
\hline Itália & 21 & 1,32 & 5 & 3,47 & 5 & 5,75 \\
\hline Argentina & 19 & 1,20 & 5 & 3,47 & 4 & 4,60 \\
\hline Colômbia & 19 & 1,20 & 8 & 5,56 & 7 & 8,05 \\
\hline Portugal & 15 & 0,95 & 3 & 2,08 & 1 & 1,15 \\
\hline França & 6 & 0,38 & 6 & 4,17 & 6 & 6,90 \\
\hline Alemanha & 5 & 0,32 & 3 & 2,08 & 2 & 2,30 \\
\hline Chile & 5 & 0,32 & 3 & 2,08 & 3 & 3,45 \\
\hline Bolívia & 4 & 0,25 & 1 & 0,69 & 1 & 1,15 \\
\hline Suíça & 3 & 0,19 & 1 & 0,69 & 0 & 0,00 \\
\hline Bélgica & 1 & 0,06 & 1 & 0,69 & 1 & 1,15 \\
\hline Escócia & 1 & 0,06 & 1 & 0,69 & 1 & 1,15 \\
\hline TOTAL & $\mathbf{1 5 8 6}$ & $\mathbf{1 0 0 , 0 0}$ & $\mathbf{1 4 4}$ & $\mathbf{1 0 0 , 0 0}$ & $\mathbf{8 7}$ & $\mathbf{1 0 0 , 0 0}$ \\
\hline
\end{tabular}

Fonte: Dados da pesquisa (2018)

Segundo Leta (2012) com o aumento de publicações no Brasil houve uma maior participação e indexação de novos títulos brasileiros nas bases de dados Web of Science e Scopus. Na mesma linha, Mugnaini, Digiampietri e Mena-Chalco (2014, p. 243) afirmam que: “a maior presença de revistas brasileiras implicou aumento do número de artigos, e consequentemente, maior representatividade da pesquisa nacional na WoS". 0 que acontece, também, na área de História, pois elevando o número de 
publicações indexadas a tendência é que a visibilidade dos artigos seja ampliada e também as citações recebidas e os índices das revistas sejam melhorados, inclusive o Qualis.

Observa-se também que Inglaterra e Estados Unidos apresentam o maior número de periódicos com artigos publicados, ambos com 27 (18,75\%) títulos cada, e respectivamente com 53 e 48 artigos publicados; seguido do Brasil e da Espanha com 20 títulos (13,89\%) cada, e respectivamente com 1241 e 51 artigos publicados e Holanda com 12 (8,33\%) periódicos e 46 artigos publicados. Pode-se notar a proximidade da área de História com o estudo de Packer (2011), onde os Estados Unidos seguido da Inglaterra e Holanda lideram a lista dos periódicos de todas as áreas do conhecimento indexados, em 2010, na WoS. Importante distinguir a diferença da concentração de periódicos e de artigos. Mesmo com o maior número de títulos em editoras estrangeiras, identifica-se notável concentração dos artigos nos títulos brasileiros, o que aponta para a necessidade de se considerar as duas unidades: artigos e periódicos nas análises, pois a apenas dispersão dos títulos mostra uma visão insuficiente e superficial da situação das publicações da área.

Quanto às editoras, observou-se que 17 (19,54\%) são do Brasil e publicaram 1241 artigos, 15 $(17,24 \%)$ são da Espanha e publicaram 51 artigos, 13 (14,94\%) são dos Estados Unidos e publicaram 48 artigos e nove (10,34\%) são da Inglaterra e publicaram 53 artigos. Para as editoras optou-se por contabilizar os países sede para contagem, por isso totaliza 87 editoras, pois cada editora possui apenas um país como sede principal. Os resultados mostram que no Brasil a maioria das editoras tem apenas um periódico, característico do modelo brasileiro onde universidades e associações científicas atuam como instituições editoras. Já na Holanda apenas a comercial Elsevier tem 12 títulos, o que mostra o modelo dominado pelas grandes editoras comerciais, com grande número de títulos por área do conhecimento.

Os dados da Tabela 05, a seguir, mostram as 31 editoras com maior número de títulos ou com mais de 25 artigos publicados, com sua tipificação editorial e o número de artigos publicados.

As editoras comerciais Springer e Taylor \& Francis apresentam o maior número de títulos de periódicos, ambas com 15 (10,42\%) títulos cada. Em seguida ficou a editora universitária Cambridge University Press, com oito (5,56\%) títulos indexados; a editora comercial Sage Publications com seis $(4,17 \%)$ títulos indexados. Chama-se atenção ao fato de que a editora classificada como instituição de pesquisa Fundação Oswaldo Cruz, com apenas um (0,69\%) título de periódico indexado possui a maior quantidade de artigos, 211 (13,30\%), seguida das editoras universitárias, ambas com dois (1,39\%) títulos de periódicos indexados, Universidade Federal Paulista e Universidade Federal do Rio Grande do Sul, respectivamente com 134 (8,45\%) e 105 (6,62\%) dos artigos publicados. 
Tabela 05 - Editoras com mais de um título indexado na WoS ou com mais de 25 artigos publicados, quadriênio 2013 a 2016, com sua tipificação editorial e número de artigos publicados

\begin{tabular}{|c|c|c|c|c|c|}
\hline \multirow[t]{2}{*}{ Editoras } & \multirow[t]{2}{*}{ Tipo } & \multicolumn{2}{|c|}{ Periódicos } & \multicolumn{2}{|c|}{ Artigos } \\
\hline & & $\mathbf{N}$ & $\%$ & $\mathbf{N}$ & $\%$ \\
\hline Springer & Comercial & 15 & 10,42 & 53 & 3,34 \\
\hline Taylor \& Francis & Comercial & 15 & 10,42 & 35 & 2,21 \\
\hline Cambridge Univ Press & Universitária & 8 & 5,56 & 20 & 1,26 \\
\hline Sage Publications & Comercial & 6 & 4,17 & 10 & 0,63 \\
\hline $\begin{array}{l}\text { Consejo Superior De Investigaciones } \\
\text { Cientificas }\end{array}$ & Instituição de Pesquisa & 3 & 2,08 & 8 & 0,50 \\
\hline Elsevier & Comercial & 3 & 2,08 & 7 & 0,44 \\
\hline Oxford Univ Press & Universitária & 3 & 2,08 & 3 & 0,19 \\
\hline Univ Coimbra & Universitária & 3 & 2,08 & 15 & 0,95 \\
\hline Berghahn Journals & Universitária & 2 & 1,39 & 2 & 0,13 \\
\hline Univ Complutense Madrid & Universitária & 2 & 1,39 & 3 & 0,19 \\
\hline Univ Estadual Paulista & Universitária & 2 & 1,39 & 134 & 8,45 \\
\hline Univ Fed Fluminense & Universitária & 2 & 1,39 & 104 & 6,56 \\
\hline Univ Federal Rio Grande Sul & Universitária & 2 & 1,39 & 105 & 6,62 \\
\hline Univ Nac Colombia & Universitária & 2 & 1,39 & 3 & 0,19 \\
\hline Univ Nac La Plata & Universitária & 2 & 1,39 & 2 & 0,13 \\
\hline Univ Salamanca & Universitária & 2 & 1,39 & 6 & 0,38 \\
\hline Wiley-Blackwell & Comercial & 2 & 1,39 & 3 & 0,19 \\
\hline Fundacão Oswaldo Cruz & Instituição de Pesquisa & 1 & 0,69 & 211 & 13,30 \\
\hline Univ Do Vale Do Rio Dos Sinos & Universitária & 1 & 0,69 & 98 & 6,18 \\
\hline Assoc Nac História & Associação & 1 & 0,69 & 95 & 5,99 \\
\hline Univ Estadual Londrina & Universitária & 1 & 0,69 & 66 & 4,16 \\
\hline Univ Estado Santa Catarina & Universitária & 1 & 0,69 & 64 & 4,04 \\
\hline Univ Federal Ouro Preto & Universitária & 1 & 0,69 & 51 & 3,22 \\
\hline $\begin{array}{l}\text { Centro Documentacion Historica Rio } \\
\text { Plata Prof Dr Walter Rela }\end{array}$ & Instituição de Pesquisa & 1 & 0,69 & 48 & 3,03 \\
\hline Univ Brasilia & Universitária & 1 & 0,69 & 48 & 3,03 \\
\hline Univ Caxias Sul & Universitária & 1 & 0,69 & 47 & 2,96 \\
\hline $\begin{array}{l}\text { Pontificia Universidade } \\
\text { Catolica Do Rio Grande Sul }\end{array}$ & Universitária & 1 & 0,69 & 45 & 2,84 \\
\hline Pontificia Univ Catolica Minas Gerais & Universitária & 1 & 0,69 & 41 & 2,59 \\
\hline Univ Federal Rio De Janeiro & Universitária & 1 & 0,69 & 41 & 2,59 \\
\hline Univ Passo Fundo & Universitária & 1 & 0,69 & 34 & 2,14 \\
\hline Pontificia Univ Catolica Sao Paulo & Universitária & 1 & 0,69 & 33 & 2,08 \\
\hline Outros & Diversas & 56 & 38,89 & 151 & 9,52 \\
\hline Total & & 144 & 100,00 & 1586 & 100,00 \\
\hline
\end{tabular}

Fonte: Dados da Pesquisa (2018)

Outros: Estão incluídas 56 editoras com apenas um título de periódico indexado e com até 25 artigos publicados em cada, engloba 15 editoras de associações, sete editoras comerciais, 33 editoras universitárias e uma do governo. 
Do total de 87 editoras identificadas, a maioria (55 ou 63,22\%) são universitárias, seguidas das comerciais e de associações com $12(13,79 \%)$ editoras cada, e instituições de pesquisa com sete (8,05\%) editoras. 0 estudo realizado por Rodrigues, Salm e Neubert (2017) na área de agricultura, no Brasil, obteve resultados semelhantes em relação a concentração de periódicos publicados por editoras comerciais (50,55\%) e destas 16,48\% (30) dos títulos são publicados pela Elsevier, $11,54 \%$, (21) pela Springer e 10,98\% (20) pela Wiley-Blackwell.

Segundo Guédon (2001) as editoras comerciais dominam o mercado de publicação de periódicos desde o século XVIII, o que resultou na chamada crise dos periódicos e 0 início pelo movimento do acesso aberto. No Brasil o movimento de acesso aberto é muito relevante, por isso o grande número de editoras universitárias que não cobram taxas aos autores, tendo em vista que a pesquisa analisou um total de 1586 artigos da área de História com pelo menos um autor brasileiro, publicados em 144 periódicos, 0 que contabilizou o total de 87 editoras.

\section{CONCLUSÃO}

Observou que a área de História tem 52 títulos classificados como A1 no Qualis e que o país que possui maior número de periódicos nesse estrato é o Brasil, com um total de 18 títulos $(34,62 \%)$, seguido do Reino Unido, com 15 títulos (28,85\%) e Estados Unidos, com oito títulos (15,38\%); as editoras universitárias, por sua vez, são as responsáveis pelo maior número de periódicos, com 23 (44, 23\%) do total. Quanto ao tipo de acesso dos periódicos de estrato A1 na área de História do Qualis, quadriênio 2013 a 2016, verificou-se que dos 52 (100\%) dos periódicos, 25 (48,08\%) são de acesso aberto sem taxas, $23(44,23 \%)$ periódicos com subscrição com opção de taxas de autor e quatro $(7,69 \%)$ com subscrição.

Os títulos A1 da História estão alinhados com os trabalhos de Rodrigues e Abadal (2014), Mueller,(2010), Mugnaini, Digiampietri e Mena-Chalco (2014) e Packer (2014) pois verificou-se que, predominantemente, os periódicos brasileiros estão em Acesso Aberto sem cobrança de taxas aos autores e são publicados por editoras universitárias. A variação é sobre o número de títulos brasileiros indexados no estrato $\mathrm{A} 1$, que varia segundo a área do conhecimento e, sendo a História ligada à grande área de Humanidades, provavelmente tem um maior número de títulos nacionais no estrato.

Verificou-se os títulos indexados na WoS nos quais houveram publicações de autores brasileiros da área de História, onde foi constatado que os periódicos com a maior quantidade de artigos indexados 
são Qualis A1. Os periódicos com maior número de artigos são: História, Ciências, Saúde - Manguinhos com 211 (13,30\%) artigos; seguido de História UNISINOS com 98 (6,18\%) artigos e a Revista Brasileira de História com 95 (5,99\%) artigos.

Ainda na segunda parte da pesquisa, em relação aos países com maior número de publicação de artigos, o Brasil se destaca com 1241 (78,25\%) artigos, seguido pela Inglaterra com 53 (3,34\%\%) artigos, Espanha com 51 (3,22\%) artigos, Estados Unidos e Uruguai com 48 (3,03\%) artigos cada um e Holanda com 46 (2,90\%) artigos.

Identificou-se 31 editoras com mais de um título de periódicos indexados na WoS ou com mais de 25 artigos publicados, quadriênio 2013 a 2016, onde as editoras comerciais Springer e Taylor \& Francis obtiveram o maior número de títulos de periódicos indexados, ambas com 15 (10,42\%) títulos cada. Do total das 87 editoras, 55 (63,22\%) são universitárias, seguidas das comerciais e de associações com $12(13,79 \%)$ editoras cada, e instituições de pesquisa com sete $(8,05 \%)$ editoras.

Com os resultados apresentados é possível concluir que na área de História a maioria dos 52 títulos registrado como Qualis A1 são brasileiros (35\%), e editados por universidades, seguido dos títulos ingleses com 29\% editados na maioria por empresas comerciais. A presença de grande número de títulos brasileiros como A1 é especificidade da área de História, diferente das Ciências Agrarias, Saúde e Biologia, mas provavelmente se aplica à outras áreas das Ciências Humanas. Foi identificada uma distribuição de artigos concentrada em periódicos brasileiros, a maioria editada por universidades e associações científicas e em acesso aberto sem cobrança de taxas aos autores. A concentração dos artigos em títulos brasileiros foi identificada em outras áreas do conhecimento e pode ser considerada equivalente ao cenário geral brasileiro, o destaque dos títulos em acesso aberto sem taxas aos autores pode ser creditado ao contexto da América Latina, especialmente ao Brasil e não às especificidades da área do conhecimento.

\section{REFERÊNCIAS}

ABADAL, E. Acceso abierto a la ciência. Editorial UOC: Barcelona, 2012.

BENTHIEN, R. F. Qualis periódicos na área de história: alguns apontamentos sobre os pressupostos, os resultados e os possíveis efeitos de uma avaliação institucional (2013-2016). Blog Observatório da História. 20 nov. 2018. Disponível em: https://histobs.hypotheses.org/614. Acesso em: 23 maio 2019. 
CINTRA, P. R.; FURNIVAL, A. C.; MILANEZ, D. H. 0 acesso aberto à luz dos estudos sociais da ciência e tecnologia. Encontros Bibli: Revista Eletrônica de Biblioteconomia e Ciência da Informação, v. 22, n. 50, p. 205-222, 2017. Disponível em: http://www.brapci.inf.br/index.php/res/v/35466?fbclid=lw AR3zHqJCcAyMgPoTEZQzW27jyRCJ9iOzT7EXF1PzXtl1ELPjrmFr7I8oZHY. Acesso em: 05 nov. 2018.

COLLAZO-REYES, F. Growth of the number of indexed journals of Latin America and the Caribbean: the effect on the impact of each country. Scientometrics, v. 98, n. 1, p.197-209, 2014. Disponível em: https//10.1007/s11192-013-1036-2. Acesso em: 15 maio 2019.

COLEMAN, A. Self-archiving and the Copyright Transfer Agreements of ISI-ranked library and information science journals. Journal of the American Society for Information Science and Technology. v. 58, n. 2, p. 286-296, 2007. Disponível em: https://doi.org/10.1002/asi.20494. Acesso em: 28 maio 2018.

COSTA, A. L. F.; YAMAMOTO, 0. H. Publicação e avaliação de periódicos científicos: paradoxos de avaliação Qualis de psicologia. Psicologia em Estudo, Maringá, v. 13. n. 1, p. 13 - 24, jan./mar. 2008. Disponível em: http://www.scielo.br/scielo.php?pid=S1413-73722008000100003\&script=sci_ abstract\&tlng=pt. Acesso em: 27 maio 2018.

CRESWELL, J. W. Projeto de pesquisa: métodos qualitativo, quantitativo e misto. 3. ed. Porto Alegre: ARTMED, 2010.

ERDMANN, A. L. et al. A avaliação de periódicos científicos qualis e a produção brasileira de artigos da área de enfermagem. Revista Latino-Americana de Enfermagem, Ribeirão Preto, v. 17, n. 3, p. 403-409, jun. 2009. Disponível em: http://www.scielo.br/scielo.php?script=sci_arttext\&pid=S0104$11692009000300019 \&$ Ing=en\&nrm=iso. Acesso em: 21 maio 2018.

FICO, C.; WASSERMAN, C.; MAGALHÃES, M. S. Expansão e avaliação da área de história: 20102016. Hist. Historiogr., v. 11, n. 28, set/dez 2018, p. 267-302. Disponível em: http://D0I: 10.15848/ hh.v0i28.1393. Acesso em: 22 maio 2019.

GUÉDON, Jean-Claude. OIdenburg's Long Shadow: Librarians, Research Scientists, Publishers, and the Control of Scientific Publishing, Association of Research Libraries. 2001. Disponível em: http:// www.arl.org/resources/pubs/mmproceedings/138guedon.shtml. Acesso em: 27 maio 2018.

LARIVIÈRI, V.; HAUSTEIN, S; MONGEON, P. The oligopoly of academic publishers in the digital era. PLOs One, v. 10, n. 6, 2015. Disponível em: http://journals.plos.org/plosone/article?id=10.1371/ journal.pone.0127502. Acesso em: 27 maio 2018.

LEITE, F. B.; CODATO, A. Autonomização e institucionalização da Ciência política brasileira: 0 papel do sistema Qualis-Capes. Agenda Política, v. 1, p. 01-21, 2013. Disponível em: http://www. agendapolitica.ufscar.br/index.php/agendapolitica/article/view/10. Acesso em: 28 maio 2018.

LETA, J. Brazilian growth in the mainstream science: The role of human resources and national journals. Journal Of Scientometric Research, v. 1, n. 1, p.44-52, 2012. Disponível em: https// doi:10.5530/jscires.2012.1.9. Acesso em: 15 maio 2019.

LINS, M. P. E.; PESSÔA, L. A. M. Desafios da avaliação de publicações em periódicos: discutindo 0 novo Qualis da Área Engenharias III. Revista Brasileira de Pós-Graduação, Brasília, v.7, n.12, p. 
14-33, jul. 2010. Disponível em: http://ojs.rbpg.capes.gov.br/index.php/rbpg/article/view/179. Acesso em: 20 maio 2018.

LÓPEZ-COZAR, E. D. Evaluar revistas científicas: un afán com mucho presente y passado e incerto futuro. ABADAL, Ernest (Org.). Revistas científicas: situación actual y retos de futuro. Barcelona: Editora da Universidade de Barcelona, 2017.

MCGUIGAN, G. S.; RUSSEL, R. D. The business of academic publishing: a strategic analysis of the academic journal publishing industry and its impact on the future of scholarly publishing.

Electronic Journal of Academic and Special Librarianship, v. 9, n. 3, 2008. Disponível em: http:// southernlibrarianship.icaap.org/content/v09n03/mcguigan_g01.html. Acesso em: 28 maio 2018.

MEADOWS, A J. Communicating research. London: Academic Press, 1998.

MERTON, R. Ensaios de sociologia da ciência. São Paulo: Associação Filosófica Scientiae Studia; Ed. 34, 2013.

MINISTÉRIO DA EDUCAÇÃO - MEC. Coordenação de Aperfeiçoamento de Pessoal de Nível Superior - CAPES. Diretoria de Avaliação. Considerações sobre Qualis Periódicos: história. [Brasília]: [s./n.], 2016a. Disponível em: http://www.capes.gov.br/images/documentos/Qualis_periodicos_2016/ Consideracoes_Qualis_Periodicos_Area_40_2016_08_08_HIST\%C3\%93RIA.pdf. Acesso em: 27 maio 2018.

MINISTÉRIO DA EDUCAÇÃO - MEC. Coordenação de Aperfeiçoamento de Pessoal de Nível Superior CAPES. Diretoria de Avaliação. Documento da área: história. [Brasília]: [s./n.], 2016b. Disponível em: http://www.capes.gov.br/images/documentos/Documentos_de_area_2017/40_hist_docarea_2016. pdf. Acesso em: 27 maio 2018.

MINISTÉRIO DA EDUCAÇÃO - MEC. Coordenação de Aperfeiçoamento de Pessoal de Nível Superior CAPES. Qualis. [Brasília]: [s./n.], 2017. Disponível em: http://www.capes.gov.br/acessoainformacao/ perguntas-frequentes/avaliacao-da-pos-graduacao/7422-qualis. Acesso em: 27 maio 2018.

MINISTÉRIO DA EDUCAÇÃO - MEC. Coordenação de Aperfeiçoamento de Pessoal de Nível Superior - CAPES. Classificação da produção intelectual. [Brasília]: [s./n.], 2018. Disponível em: http://www. capes.gov.br/avaliacao/instrumentos-de-apoio/classificacao-da-producao-intelectual. Acesso em: 27 maio 2018.

MINNITI, S.; SANTORO, V.; BELLI, S. Mapping the development of Open Access in Latin America and Caribbean countries. An analysis of Web of Science Core Collection and SciELO Citation Index (2005-2017). Scientometrics, v. 117, p. 1905-1930, 2018. Disponível em: https://doi.org/10.1007/ s11192-018-2950-0. Acesso em: 14 maio 2019.

MUELLER, S.P.M. Produção e financiamento de periódicos científicos de acesso aberto: um estudo na base SciELO. In: FERREIRA, S.M.; TARGINO, M.G. (Eds.) Acessibilidade e visibilidade de revistas científicas eletrônicas. p. 70-118. São Paulo: SENAC/CENGAGE, 2010.

MUELLER, S. P. M.; OLIVEIRA, H. V. de. Autonomia e dependência na produção da ciência: uma base conceitual para estudar relações na comunicação científica. Perspectivas em Ciência da Informação, 
Belo Horizonte, v. 8, n. 1, p. 58-65, jan./jun. 2003. Disponível em: http://portaldeperiodicos.eci.ufmg. br/index.php/pci/article/view/374/192. Acesso em: 22 mar. 2018.

MUGNAINI, R; DIGIAMPIETRI, L. A.; MENA-CHALCO, J. P. Comunicação científica no Brasil (19982012): indexação, crescimento, fluxo e dispersão. Transinformação, vol. 26, n. 3, 2014, p. 239-252. Disponível em: https://www.redalyc.org/pdf/3843/384340897002.pdf. Acesso em: 21 maio 2019.

MUGNAINI, R; POBLACIÓN, D. A. de M. A. Multidisciplinaridade e especificidade na comunicação científica: discussão do impacto na avaliação de diferentes áreas. RECIIS - Revista eletrônica de comunicação, informação \& inovação em saúde, v. 4, p. 3, 2010. Disponível em: https://www.reciis. icict.fiocruz.br/index.php/reciis/article/view/533. Acesso em: 28 maio 2018.

NEUBERT, Patrícia da Silva ; RODRIGUES, Rosângela ; MULLER, Y. R. . Periódicos científicos de ciências biológicas: estudo dos títulos classificados no estrato A1 do Qualis. RECIIS - Revista Eletrônica de Comunicação, Informação \& Inovação em Saúde, v. 11, p. 1, 2017.

OLIVEIRA, A. B. de; RODRIGUES, R. S.; MATIAS, M. Periódicos científicos das Ciências Agrárias: análise dos títulos brasileiros indexados na Web of Science e Scopus. Perspectivas em Ciência da Informação, Belo Horizonte, v. 22, n. 2, p. 3-28, jun. 2017. Disponível em http://www.scielo.br/scielo. php?script=sci_arttext\&pid=S1413-99362017000200003\&Ing=pt\&nrm=iso. Acesso em 28 nov. 2018.

PACKER, A. L. A eclosão dos periódicos do Brasil e cenários para o seu porvir. Educ. Pesqui., São Paulo, v. 40, n. 2, p. 301-323, abr./jun. 2014. Disponível em: http://www.scielo.br/pdf/ep/v40n2/ v40n2a02.pdf. Acesso em: 21 maio 2019.

PACKER, A. L. Os periódicos brasileiros e a comunicação da pesquisa nacional. Revista USP, n. 89. 2011. Disponível em: http://rusp.scielo.br/scielo.php?script=sci_arttext\&pid=S010399892011000200004\&lng=pt\&nrm=iso. Acesso em: 28 maio 2018.

PACKER, A. L.; MENEGHINI, R. 0 SciELO aos 15 anos: raison d'être, avanços e desafios para 0 futuro. In: PACKER, A.L., et al. (Orgs.) SciELO - 15 Anos de Acesso Aberto: um estudo analítico sobre Acesso Aberto e comunicação científica. Paris: Unesco; 2014. p. 15-28. Disponível em: http://dx.doi. org/10.7476/9789237012376. Acesso em: 04 nov. 2018.

RODRIGUES, R. S.; ABADAL, E. Scientific journals in Brazil and Spain: Alternative publishing models. Journal of the Association for Information Science and Technology, v. 65, p. 2145-2151, 2014. Disponível em: http://dx.doi.org/10.1002/asi.23115. Acesso em: 28 maio 2018.

RODRIGUES, R. S.; SALM, J. ; NEUBERT, P. S . Publicação científica brasileira na área de agricultura: estudo dos artigos indexados em web of science. In: ENCONTRO NACIONAL DE PESQUISA EM CIÊNCIA DA INFORMAÇÃO, 18.,2017, Marília. Anais ... Marília: Universidade Estadual Paulista "Julio de Mesquita Filho, 2017. Disponível em:http://enancib.marilia.unesp.br/index.php/xviiienancib/ ENANCIB/paper/viewFile/84/1051. Acesso em: 22 maio 2019.

RODRIGUES, R.; OLIVEIRA, A.B. Periódicos científicos na America Latina: títulos em acesso aberto indexados no ISI e Scopus. Perspectivas em Ciência da Informação, v. 17, p.76-99, 2012. Disponível em: http://portaldeperiodicos.eci.ufmg.br/index.php/pci/article/view/1593/1100. Acesso em: 14 maio 2019. 
ROSA, F. et al. A presença das editoras universitárias nos acervos dos repositórios institucionais. InCID: Revista Ciência da Informação e Documentação, Ribeirão Preto, v. 4,

n. 2, Ed. esp., p. 152-164, jul./dez. 2013. Disponível em: https://www.revistas.usp.br/incid/article/ view/69307/71782. Acesso em: 11 maio 2019.

SAMPIERI, R. H.; COLLADO, C. F.; LUCIO, P. B. Metodologia de Pesquisa. São Paulo: McGraw-Hill, 2006.

SHILS, E. Centro e periferia. Tradução de José Hartuig de Freitas. Lisboa: DIFEL, 1992.

SILVA, F. M. et. al. Análise das comunidades de pesquisadores brasileiros que atuam na área da filosofia: um estudo a partir da justaposição entre os dados da Plataforma Lattes e Web of Science (2007-2016). Inf. \& Soc.:Est., João Pessoa, v.28, n.3, p. 245-262, set./dez. 2018. Disponível em: http://www.periodicos.ufpb.br/ojs2/index.php/ies/article/view/41223. Acesso em: 15 maio 2019.

UNESCO. Unesco Science Report: towards 2030. Paris: United Nations Educational, Scientific and Cultural Organization. 2015. Disponível em: https://en.unesco.org/usr-contents. Acesso em: 05 out. 2018.

WHITLEY, R. The Intelectual and Social Organization of the Sciences. Oxford: Oxford Press, 1984. ZIMAN, J. Conhecimento público. Belo Horizonte: Itatiaia; São Paulo: EDUSP, 1979. 